\title{
Perfil genotípico e antigênico de amostras do vírus da diarréia viral bovina isoladas no Rio Grande do Sul $(2000-2010)^{1}$
}

\author{
Eloisa Bianchi², Mathias Martins ${ }^{2}$, Rudi Weiblen² e Eduardo Furtado Flores ${ }^{2 *}$
}

\begin{abstract}
Bianchi E., Martins M., Weiblen R. \& Flores E.F. 2011. [Genotypic and antigenic profile of bovine viral diarrhea virus isolates from Rio Grande do Sul, Brazil (20002010).] Perfil genotípico e antigênico de amostras do vírus da diarréia viral bovina isoladas no Rio Grande do Sul (2000-2010). Pesquisa Veterinária Brasileira 31(8):649-655. Setor de Virologia, Departamento de Medicina Veterinária Preventiva, Centro de Ciências Rurais, Universidade Federal de Santa Maria, Av. Roraima 1000, Camobi, Santa Maria, RS 97105-900, Brazil. E-mail: eduardofurtadoflores@gmail.com

Field isolates of bovine viral diarrhea virus (BVDV) display a high genetic and antigenic diversity that may difficult diagnosis and vaccine formulation. The present study presents a genetic and antigenic characterization of 20 BVDV isolates from Rio Grande do Sul, Brazil (20002010). The isolates were associated with a variety of clinical conditions that included respiratory or gastroenteric disease, skin lesions, abortions, animals with retarded growth, and persistently infected (PI) animals. Most isolates (19 or 95\%) belong to the non-cytopathic biotype (NCP), one isolate (5\%) had a mixture of viruses NCP and cytopathic (CP). Nucleotide sequencing of a region of 270 nucleotides of the 5' untranslated region of the viral genome followed by phylogenetic analysis identified nine isolates of BVDV-2 (45\%), eight BVDV-1 (40\%). Three isolates were not classified in any genotype and were classified as atypical pestiviruses. It was not possible to associate genotypes or subgenotypes with clinical conditions: both BVDV-1 and BVDV-2 were involved in different clinico - pathological syndromes. Analysis of reactivity with a panel of 19 monoclonal antibodies (mAbs) revealed a marked variability in the major envelope glycoprotein (E2/gp53) among viruses of the same genotype, but especially among viruses from different genotypes. Virus neutralization assays (VN) with antisera of BVDV-1 and BVDV2 reference strains against the isolates revealed variable levels of cross-reactivity between viruses of the same genotype, and lack or very low reactivity between viruses of different genotypes. These results indicate a similar frequency of BVDV-1 and BVDV-2 in the cattle population of Rio Grande do Sul, confirm the remarkable antigenic diversity of BVDV and reinforce the need to include viruses of genotypes BVDV- 1 and BVDV- 2 in vaccines. In addition, these results indicate the circulation of atypical pestiviruses in the cattle population of RS.
\end{abstract}

INDEX TERMS: BVDV, pestivirus, genotyping, genetic diversity.

RESUMO.- Isolados do vírus da diarréia viral bovina (BVDV) apresentam grande diversidade genética e antigênica, o que pode dificultar o diagnóstico e a formulação de vacinas. 0 presente trabalho apresenta um perfil genotípico e antigênico de 20 amostras do BVDV isoladas no Estado do Rio Grande do Sul entre 2000 e 2010. As amostras foram oriundas de uma variedade de condições clínicas, que incluíam doença respi-

\footnotetext{
${ }^{1}$ Recebido em 24 de fevereiro de 2011.

Aceito para publicação em 21 de março de 2011.

2 Setor de Virologia, Departamento de Medicina Veterinária Preventiva (DMVP), Centro de Ciências Rurais (CCR), Universidade Federal de Santa Maria (UFSM), Santa Maria, RS 97105-900, Brasil. *Autor para correspondência: eduardofurtadoflores@gmail.com
}

ratória ou gastroentérica aguda ou crônica, lesões cutâneas, abortos, animais com crescimento retardado, além de animais persistentemente infectados (PI). A maioria das amostras (19 ou 95\%) pertence ao biótipo não-citopático (NCP); enquanto um isolado apresentou uma mistura de vírus NCP e citopático (CP). 0 sequenciamento e análise filogenética de uma região de 270 nucleotídeos da região 5' não-traduzida do genoma viral permitiu identificar 9 isolados de BVDV-2 (45\%) e 8 isolados de BVDV-2 (40\%). Três amostras não agruparam filogeneticamente com nenhum dos genótipos, sendo classificados como pestivírus atípicos. Não foi possível associar os genótipos ou subgenótipos com as condições clínicas e, tanto os BVDV-1 quanto os BVDV-2 estavam envolvidos em 
diferentes síndromes clínico-patológicas. Análise de reatividade com um painel de 19 anticorpos monoclonais (AcMs) revelou uma variabilidade marcante na glicoproteína principal do envelope (E2) entre vírus do mesmo genótipo, e sobretudo, entre vírus de genótipos diferentes. Testes de neutralização viral (SN) com anti-soro de cepas de referência de BVDV-1 e BVDV-2 frente às amostras isoladas revelaram níveis variáveis de reatividade cruzada entre vírus do mesmo genótipo, e reatividade muito baixa ou ausente entre vírus de genótipos diferentes. Esses resultados indicam uma frequência semelhante de BVDV-1 e BVDV-2 na população estudada, confirmam a marcante variabilidade antigênica e reforçam a necessidade de se incluir vírus dos dois genótipos nas vacinas. Finalmente, indicam a presença de pestivírus atípicos circulantes na população bovina do RS.

TERMOS DE INDEXAÇÃO: BVDV, pestivírus, genótipos, diversidade genética.

\section{INTRODUÇÃO}

O vírus da Diarréia Viral Bovina (bovine viral diarrhea virus, BVDV) é um dos principais patógenos de bovinos, pertencente à família Flaviviridae, gênero Pestivirus (Horzinek 1991). Os pestivírus são vírus pequenos (40-60nm), envelopados e contêm uma molécula de RNA de fita simples e polaridade positiva como genoma (Collett et al. 1988, Horzinek 1991). 0 genoma do BVDV possui aproximadamente 12,5 kb e contém uma única fase aberta de leitura (ORF), que codifica uma poliproteína com 3988 aminoácidos (Collett et al. 1988). A ORF é precedida por uma região não-traduzida (5'UTR) com 360 a 390 nucleotídeos. A região 5' UTR do genoma é altamente conservada entre os Pestivirus e tem sido frequentemente utilizada para caracterização genética e filogenia de isolados de campo (Ridpath et al. 1994). Os isolados de campo do BVDV podem ser ainda classificados em biótipos citopático (CP) e nãocitopático (NCP), de acordo com a capacidade de produzir patologia em células de cultivo (Ridpath 2003).

A infecção de bovinos pelo BVDV tem sido associada com uma variedade de manifestações clínicas, que incluem desde infecções inaparentes até doença aguda fatal. Enfermidade gastroentérica aguda ou crônica, doença respiratória em bezerros, síndrome hemorrágica com trombocitopenia, patologias cutâneas e imunossupressão estão entre as consequências mais frequentes da infecção (Baker 1995). 0 BVDV também é frequentemente associado com perdas reprodutivas, como infertilidade temporária, retorno ao cio, mortalidade embrionária ou fetal, abortos ou mumificação, malformações fetais ou produção de bezerros fracos e inviáveis (Baker 1995).

A infecção pelo BVDV possui distribuição mundial e a prevalência de anticorpos chega a atingir $80 \%$ dos animais e até $80 \%$ dos rebanhos na América do Norte e em alguns países europeus. No Brasil, a infecção está amplamente distribuída em rebanhos de leite e corte e vários relatos sorológicos, clínicos e virológicos sobre a enfermidade já foram publicados (Flores et al. 2005).

Os isolados de campo do BVDV apresentam uma grande variabilidade genética. Com base nas sequências de nucleotídeos da região 5'UTR, os isolados podem ser distribuidos em dois grupos ou genótipos principais, que também são antige- nicamente distintos: BVDV-1 e BVDV-2 (Pellerin et al. 1994, Ridpath et al. 1994). Os isolados de BVDV-1 podem ser subdivididos em 11 subgenótipos (Vilcek et al. 2001), enquanto que os vírus do genótipo BVDV-2 possuem dois subgrupos principais, BVDV-2a e BVDV-2b (Flores et al. 2002). Os vírus do genótipo 1 (BVDV-1) ainda representam a maioria dos isolados de campo na América do Norte, Europa e Austrália (Ridpath et al. 2010). Os vírus do genótipo BVDV-2 foram identificados há pouco mais de uma década em surtos de doença gastroentérica na América do Norte (Pellerin et al 1994), mas encontram-se disseminados por vários continentes (Vilcek et al 2001, Becher et al. 2003, Minami et al. 2009, Ridpath et al. 2010). Há alguns anos, um Pestivirus atípico (D32/00_'HoBi'), que vem sendo provisoriamente denominado BVDV-3, foi identificado em uma amostra de soro fetal bovino oriunda do Brasil (Schirrmeier et al. 2004). Estudos posteriores revelaram a presença desses pestivírus atípicos em outros continentes (Schirrmeier et al. 2004, Stalder et al. 2005, 2007).

A grande variabilidade antigênica existente entre isolados de BVDV deve-se principalmente a marcante plasticidade da glicoproteína E2 (ou gp53). A E2 é a glicoproteína mais abundante do envelope viral, está envolvida na ligação dos vírions aos receptores celulares e se constitui no principal alvo para anticorpos neutralizantes (Donis 1995, Ridpath 2003, 2004). $A$ variabilidade na $\mathrm{E} 2$ pode ser facilmente evidenciada por testes de neutralização cruzada e, também, por reatividade diferencial com anticorpos monoclonais (Ridpath 2003). A variabilidade da E2 ocorre entre amostras de um mesmo genótipo e, sobretudo, entre vírus de genótipos diferentes. Com isso, a reatividade sorológica entre vírus dos genótipos BVDV-1 e BVDV-2 é geralmente muito baixa (Ridpath 2003, 2004). Essa grande variabilidade antigênica possui implicações potenciais para o diagnóstico e para a formulação de vacinas (Ridpath 2003).

Estudos anteriores caracterizaram geneticamente amostras de campo do BVDV isoladas no Brasil, e vírus dos dois genótipos foram identificados (Canal et al. 1998, Gil 1998, Flores et al. 2002, 2005, Cortez et al. 2006). Não obstante, a caracterização contínua de isolados é importante para o conhecimento do perfil dos vírus presentes, e também para a eventual identificação de outros genótipos ou subgenótipos circulantes. Assim, o presente artigo relata a tipificação genética de 20 amostras do BVDV isoladas no Rio Grande do Sul entre 2000 e 2010, por meio de sequenciamento e análise filogenética de uma seqüência da região 5' UTR. Também foram investigadas a reatividade desses isolados com um painel de AcMs, e a sua reatividade sorológica com anti-soro produzido contra vírus dos genótipos BVDV-1 e BVDV-2.

\section{MATERIAL E MÉTODOS}

Vinte amostras de BVDV isoladas no Setor de Virologia da Universidade Federal de Santa Maria (SV/UFSM), entre os anos de 2000 e 2010, oriundas de vários municípios do Estado do Rio Grande do Sul, foram submetidas a sequenciamento e e análise filogenética da região 5'UTR, análise de reatividade com anticorpos monoclonais (AcMs) e testes de neutralização cruzada com anti-soro produzido com cepas de BVDV-1 e BVDV-2.

Células e vírus. Os procedimentos de isolamento, amplificação viral e clonagem biológica foram realizados em células de li- 
nhagem de rim bovino (MDBK) livres de Pestivirus. As células foram cultivadas em meio essencial mínimo (MEM), suplementado com $10 \%$ de soro equino, estreptomicina ${ }^{a}\left(0,4 \mathrm{mg} \cdot \mathrm{mL}^{-1}\right)$, penicilina ${ }^{\mathrm{a}}$ $\left(1,6 \mathrm{mg} \cdot \mathrm{mL}^{-1}\right)$ e anfotericina $\mathrm{B}^{\mathrm{a}}\left(0,0025 \mathrm{mg} \cdot \mathrm{mL}^{-1}\right)$. Os vírus utilizados nos procedimentos foram submetidos a clonagem biológica por ensaios de placa (vírus CP) ou diluição limitante (vírus NCP).

Extração de RNA e RT-PCR. Células MDBK foram infectadas com cada amostra clonada, individualmente, em frascos de $25 \mathrm{~cm}^{2}$. Após 24 - 48h, o RNA total foi extraído das células, utilizando-se o reagente Trizol $^{\mathrm{b}}$ de acordo com instruções do fabricante. O DNA complementar (cDNA) foi sintetizado a partir do RNA total utilizando um Kit comercial SuperScript ${ }^{T M} I I I R T^{\mathrm{b}}$, o qual serviu de molde para a reação em cadeia da polimerase (PCR). A PCR foi realizada de acordo com as condições e primers descritos por Ridpath \& Bolin (1998). A reação resulta na amplificação de fragmento de 270 pb localizado na região 5’UTR do genoma viral.

Sequenciamento e análise filogenética. Os produtos da amplificação por PCR foram purificados com o uso do Kit comercial PCR PureLink ${ }^{\mathrm{b}}$ e submetidos ao sequenciamento em duplicata e processados em sequenciador automático MEGABACE 1000. A pureza das sequências foi avaliada pelo programa Staden Package, sendo então alinhadas para a obtenção de uma sequência consenso e posteriormente submetidas ao BLAST (Basic Local Alignment Search Tool) para comparação com sequências depositadas no GenBank, classificando os isolados em dois genótipos. 0 alinhamento das sequências e a construção da árvore filogenética dos isolados, cepas padrão do BVDV e cepas de referência para BDV e CSFV foram realizadas utilizando o programa MEGA 4.1 (Tamura et al. 2007) pelo método Neighboor-Joinning com 1000 réplicas de bootstrap, modelo Maximum Composite Likelihood.

Reatividade com anticorpos monoclonais. Para investigarse a variabilidade antigênica dos isolados, utilizou-se dois painéis de AcMs específicos para a glicoproteína E2 (Corapi et al. 1990, Ridpath et al. 2000). Células MDBK infectadas com cada isolado foram tripsinizadas, ressuspendidas, depositadas sobre lâminas multispot e deixadas aderir. Após, foram fixadas em acetona e submetidas a imunofluorescência indireta (IFA), de acordo com protocolos-padrão (Botton et al. 1998). Utilizaram-se os AcMs individuais como anticorpo primário, e um anticorpo secundário anti-IgG de camundongo conjugado com fluoresceína (Sigma-Aldrich). Células MDBK infectadas com cepas padrão, e células não infectadas, foram utilizadas como controles.

Reatividade sorológica cruzada. Para investigar-se a reatividade sorológica cruzada, utilizou-se anti-soro produzido em bezerros contra duas cepas de referência de BVDV (BVDV-1 Singer; BVDV2 VS253) e com isolados brasileiros de BVDV (BVDV-1 IBSP-2; BVDV2 SV26/2).Inicialmente, os anti-soros foram testados contra os respectivos vírus homólogos e o seu título neutralizante foi ajustado para 80/160. Somente então foram testados frente aos 20 isolados. Os testes de soro-neutralização (SN) foram realizados em microplacas de acordo com protocolos-padrão (Botton et al. 1998). Foram testadas diluições crescentes dos anti-soros frente a doses constantes $\left(100-200\right.$ DICC $_{50}$ [doses infectantes para $50 \%$ dos cultivos celulares]) de cada amostra viral. A leitura foi realizada após 96h de incubação, submetendo-se as microplacas com os tapetes celulares à técnica de imunoperoxidase (IPX) para antígenos do BVDV, de acordo com técnica descrita por Botton et al. (1998). Considerou-se o título neutralizante a recíproca da maior diluição de soro capaz de prevenir a replicação viral e, consequentemente, a produção de antígenos no respectivo tapete celular.

\section{RESULTADOS E DISCUSSÃO}

A origem, resumo do histórico clínico-patológico, biótipo e genótipo das 20 amostras analisadas no presente estudo es- tão apresentados no Quadro 1. As amostras foram isoladas de uma variedade de condições clínicas, já bem documentadas como conseqüências da infecção pelo BVDV (Baker 1995). Nove amostras (45\%) foram identificadas como BVDV-2 e oito (40\%) como BVDV-1. Três amostras não agruparam filogeneticamente com nenhum dos genótipos, sendo provisoriamente classificadas como pestivírus atípicos (Quadro 1, Fig.1). Uma dessas amostras foi isolada de sêmen industrializado, e a data que consta no Quadro 1 (2009) refere-se ao isolamento e não à data de coleta.

Em geral, não foram observadas associações evidentes entre os genótipos e condições clínicas específicas, pois vírus de ambos os genótipos foram isolados de diferentes manifestações clínicas. A proporção de amostras NCP e CP isoladas no presente estudo reflete, em parte, a abundância relativa de vírus desses biótipos na natureza. A grande maioria das amostras que circulam a campo, associadas com uma grande variedade de condições clínicas, é de vírus NCP, considerados os "BVDV verdadeiros" (Ridpath 2003, 2005). Isolados citopáticos, que apresentam uma mistura de vírus NCP e CP geneticamente relacionados, são isolados em situações específicas, geralmente associadas com a condição clínica denominada doença das mucosas, DM (Ridpath 2003). 0 histórico clínico da amostra CP era compatível clinicamente com a DM.

Alguns estudos anteriores já haviam realizado a caracte-

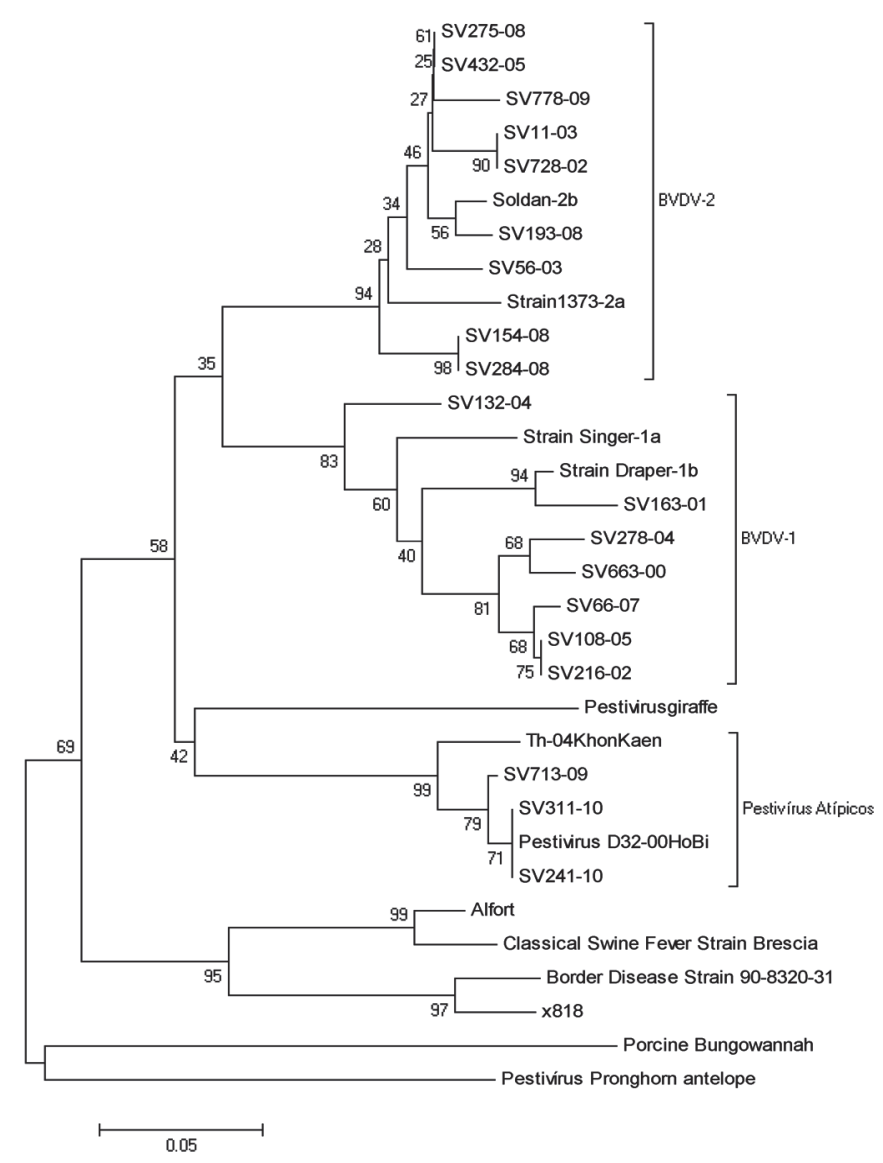

Fig.1. Árvore construída com base na análise filogenética das sequências da região 5'UTR dos diferentes isolados de BVDV do RS (2000-2010). A árvore foi construída pelo método Neighbor - Joining e pelo teste bootstrap (1000) usando o programa MEGA versão 5.0 . 
Quadro 1 Origem, histórico e características de amostras do vírus da diarréia viral bovina (BVDV) isoladas de bovinos no Rio Grande do Sul* entre 2000 e 2010

\begin{tabular}{|c|c|c|c|c|c|}
\hline $\begin{array}{l}\text { Identificação/ } \\
\text { ano }\end{array}$ & Local & Histórico & Material & Biotipo & Genótipo \\
\hline SV $663 / 00$ & Tapejara & $\begin{array}{l}\text { Bezerro com crescimento retardado, sinais respiratórios } \\
\text { recorrentes. Outros animais da propriedade foram afetados }\end{array}$ & Suabe nasal & NCP & BVDV-1a \\
\hline SV 216/02 & Porto Alegre* & Bezerro com diarréia, ulcerações no trato digestivo & $\begin{array}{l}\text { Sangue, baço, } \\
\text { pulmão, intestino }\end{array}$ & NCP & BVDV-1a \\
\hline SV $11 / 03$ & Cruz Alta & Bezerros com diarréia, propriedade de gado de corte & Sangue/tecidos & NCP & BVDV-2b \\
\hline SV $56 / 03$ & São Gabriel & $\begin{array}{l}\text { Bezerra holandesa, } 10 \text { meses, crescimento retardado, diar- } \\
\text { réia recorrente }\end{array}$ & Sangue/fezes & NCP & BVDV-2b \\
\hline SV $132 / 04$ & Júlio de Castilhos & $\begin{array}{l}\text { Propriedade com abortos }(11 / 100) \text { em fases diversas da ges- } \\
\text { tação }\end{array}$ & $\begin{array}{l}\text { Feto abortado (cére- } \\
\text { bro, timo, pulmão, } \\
\text { fígado e baço) }\end{array}$ & NCP & BVDV-1a \\
\hline SV $278 / 04$ & São Vicente do Sul & Aborto & Cérebro fetal & NCP & BVDV-1a \\
\hline SV $154 / 08$ & Porto Alegre* & Propriedade com histórico de BVD, triagem de PIs & Sangue & NCP & BVDV-2a \\
\hline SV 193/08 & Porto Alegre* & Animais positivos para BVDV em triagem por IPX na orelha & Sangue & NCP & BVDV-2b \\
\hline SV $275 / 08$ & $\begin{array}{l}\text { Nova Esperança } \\
\text { do Sul }\end{array}$ & $\begin{array}{l}\text { Propriedade com problemas reprodutivos, abortos, triagem } \\
\text { de PIs (IPX) }\end{array}$ & Sangue & NCP & BVDV-2b \\
\hline SV 284/08 & Porto Alegre** & $\begin{array}{l}\text { Propriedade com problemas reprodutivos, malformações. } \\
\text { Bezerro, } 5 \text { meses, diarréia, prostração, morte }\end{array}$ & Órgãos & NCP & BVDV-2a \\
\hline SV $436 / 08$ & Porto Alegre* & Bezerros cegos & $\begin{array}{l}\text { Baço, pulmão, } \\
\text { linfonodo mesentérico }\end{array}$ & NCP & BVDV-1a \\
\hline SV $778 / 09$ & Alegrete & Bezerros com crescimento retardado, suspeita de PI & Sangue & NCP & BVDV-2b \\
\hline SV $713 / 09$ & Porto Alegre & Bezerros nascidos cegos & Sêmen & NCP & Atípico \\
\hline SV $241 / 10$ & Caçapava do Sul & Rebanho com problemas reprodutivos & Sangue & NCP & Atípico \\
\hline SV $311 / 10$ & Santa Maria & Rebanho com problemas reprodutivos, abortos & $\begin{array}{l}\text { Pulmão e baço de } \\
\text { feto abortado }\end{array}$ & NCP & Atípico \\
\hline
\end{tabular}

* Material enviado ao Laboratório de Patologia/UFRGS. Não necessariamente oriundo do município de Porto Alegre.

rização genética de amostras de BVDV no Brasil. Canal et al. (1998) foram pioneiros na caracterização genotípica de isolados brasileiros, identificando a presença de vírus dos genótipos BVDV-1 e BVDV-2 no país. Gil (1998) analisou 18 isolados provenientes dos Estados de São Paulo, Santa Catarina e RS, identificando 14 isolados de BVDV-1 e quatro de BVDV-2. Analisando as regiões 5'UTR e NS2/3 de amostras de BVDV, Flores et al. (2002) verificaram que alguns isolados brasileiros de BVDV-2 agrupavam-se filogeneticamente distantes de isolados da Europa, Estados Unidos e Austrália, propondo a classificação de BVDV-2 em subgenótipos (BVDV-2a e BVDV2b), que foi adotada a partir de então. Cortez et al. (2006) analisaram 13 isolados de BVDV provenientes de várias regiões do Brasil, incluindo 10 amostras oriundas do RS. Dentre estas, sete (70\%) eram BVDV-1, dois isolados eram BVDV-2 e uma amostra foi identificada como pestivírus atípico (Hobilike). Como regra, estes estudos analisaram a região 5' UTR do genoma, incluíram um número restrito de isolados e identificaram uma freqüência maior de amostras de BVDV-1.

Não obstante estes estudos anteriores, o número crescente de isolamentos, a grande diversidade dos vírus de campo, assim como o recente surgimento de pestivírus atípicos (Schirrmeier et al. 2004, Stalder et al. 2005, 2007), justificam o monitoramento contínuo das características genéticas e antigênicas dos vírus circulantes na população bovina. Além do conhecimento acerca dos genótipos presentes e mais pre- valentes, as informações obtidas com o monitoramento sistemático permitem reavaliações periódicas dos procedimentos diagnósticos (cepas virais a serem utilizadas nos testes de neutralização viral, por exemplo) e da composição viral mais adequada das vacinas (Fulton et al. 2003, Ridpath 2003, 2005, Ridpath et al. 2010). A análise genética contínua de isolados de campo também permite a identificação de alterações de freqüência, distribuição temporal e espacial dos genótipos, de sua associação com diferentes síndromes clínicas e/ou detectar a introdução de novos genótipos ou subgenótipos na população (Ridpath et al. 2010). Nesse sentido, a recente identificação de pestivírus atípicos pode tornar a epidemiologia e as estratégias de diagnóstico e de controle do BVDV ainda mais complexas (Stalder et al. 2005, 2007, Ridpath et al. 2010).

0 presente estudo focou na caracterização genotípica de amostras de BVDV isoladas de uma população bovina geograficamente bem delimitada, a do Rio Grande do Sul. Em especial, os resultados obtidos indicam um aumento na freqüência de vírus do genótipo BVDV-2 em relação a estudos anteriores (Canal et al. 1998, Gil 1998, Flores et al. 2002, 2005, Cortez et al. 2006). É importante ressaltar que o presente estudo, embora analisando um número maior de amostras do que os estudos prévios, ainda envolveu uma amostragem restrita, podendo não refletir a proporção real de BVDV-1 e BVDV-2 que circulam na população bovina do RS. Segundo Ridpath (2010), é difícil precisar o número de amostras virais neces- 
sárias para se obter uma idéia aproximada da proporção relativa de genótipos e subgenótipos circulantes, mas um número mínimo de 50 isolados pode ser tomado como referência. Assim, os resultados aqui apresentados confirmam a presença de vírus dos dois genótipos na população bovina do RS, sugerem um crescimento da freqüência do BVDV-2, mas devem ser interpretados com cautela, pois podem não refletir a real proporção dos dois genótipos presentes no campo.

Sequências de nucleotídeos da região 5'UTR do genoma viral tem sido muito utilizadas para a classificação genotípica de isolados do BVDV, pelo fato de esta região ser altamente conservada entre os Pestivirus (Pellerin et al. 1994, Ridpath et al. 2004). Grupos de isolados classificados em genótipos BVDV-1 e BVDV-2 de acordo com as sequências da 5'UTR são antigenicamente distintos entre si, refletindo obviamente a existência de diferenças concomitantes em proteínas de superfície (Pellerin et al. 1994, Ridpath et al. 1994, 2010). Devido às diferenças genéticas existentes também entre os isolados de um mesmo genótipo, estudos mais recentes têm refinado essas análises. A análise concomitante da região 5’UTR com outros genes, como a N ${ }^{\text {pro, }}$ E2 e NS3 tem permitido classificar os isolados em subgrupos ou subgenótipos (Vilcek et al. 2001, Flores et al. 2002, Liu et al. 2010). No entanto, as classificações em subgenótipos/subtipos nem sempre refletem diferenças evidentes em aspectos antigênicos, epidemiológicos ou patológicos, possuindo por isso um significado prático questionável (Ridpath et al. 2010).

Os vírus do genótipo BVDV-2 foram identificados pela primeira vez há mais de duas décadas em surtos de doença gas- troentérica severa na América do Norte e, por isso, foram inicialmente considerados agentes novos (Corapi et al. 1989, Pellerin et al. 1994). Entretanto, acredita-se atualmente que os BVDV-2 circulem há muito tempo. Os vírus desse genótipo, que representam aproximadamente 50\% dos BVDV isolados nos Estados Unidos, foram retrospectivamente identificados há mais de 40 anos, e a grande maioria apresenta baixa virulência (Ridpath et al. 2004). Nos diversos estudos publicados, a proporção de BVDV-1 e BVDV-2 circulantes varia de acordo com a região. No Japão, Minami et al. (2009) encontraram maior prevalência do genótipo 1, situação semelhante foi encontrada na Austrália e nos EUA (Ridpath et al. 2010). Os resultados do presente estudo indicam uma freqüência similar dos dois genótipos (ao contrário dos outros estudos no RS e Brasil que indicavam uma maior frequência de BVDV1), mas pelo número pequeno de amostras analisadas, não devem ser considerados definitivos. Não obstante, podem refletir uma tendência, pois a freqüência de BVDV-2 tem aumentado nos últimos anos em alguns países (Ridpath et al. 2010).

Um achado relevante do presente trabalho foi a identificação de três isolados que não agruparam filogeneticamente em nenhum dos dois genótipos (BVDV-1 e BVDV-2). Embora esses dados careçam de confirmação pelo seqüenciamento de outras regiões do genoma, confirmam achados anteriores da identificação de pestivírus atípicos ou HoBi-like no Brasil (Cortez et al. 2006). A crescente identificação desses pestivírus atípicos em vários continentes tem suscitado grande preocupação de técnicos e pesquisadores em sanidade

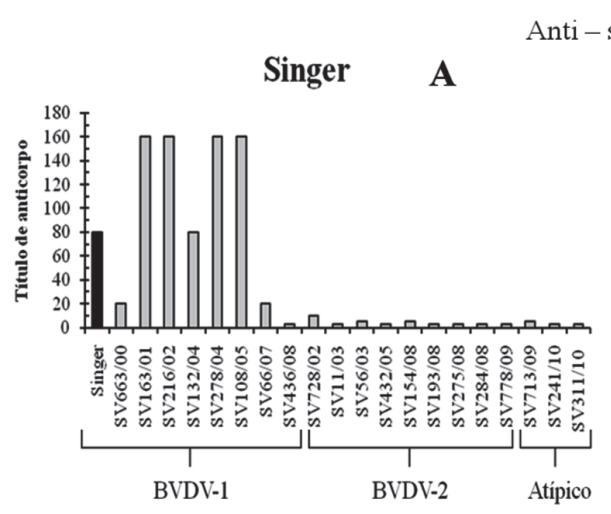

IBSP-2 B
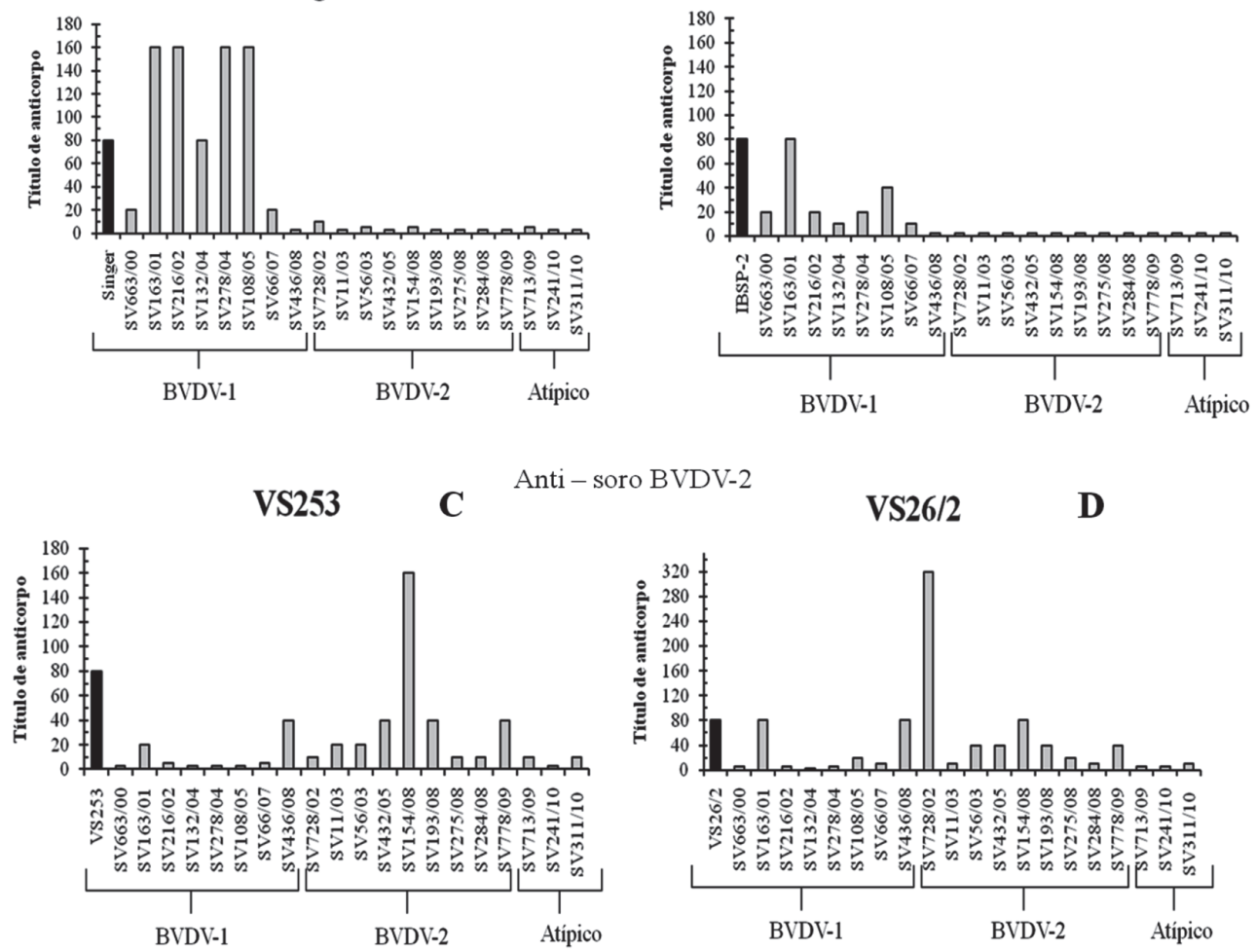

Fig.2. Atividade neutralizante de anti-soro de cepas de referência e de isolados brasileiros contra isolados de BVDV do RS (2000-2010). As barras escuras representam os títulos contra os vírus homólogos; as barras claras representam os títulos neutralizantes contra os outros isolados. 


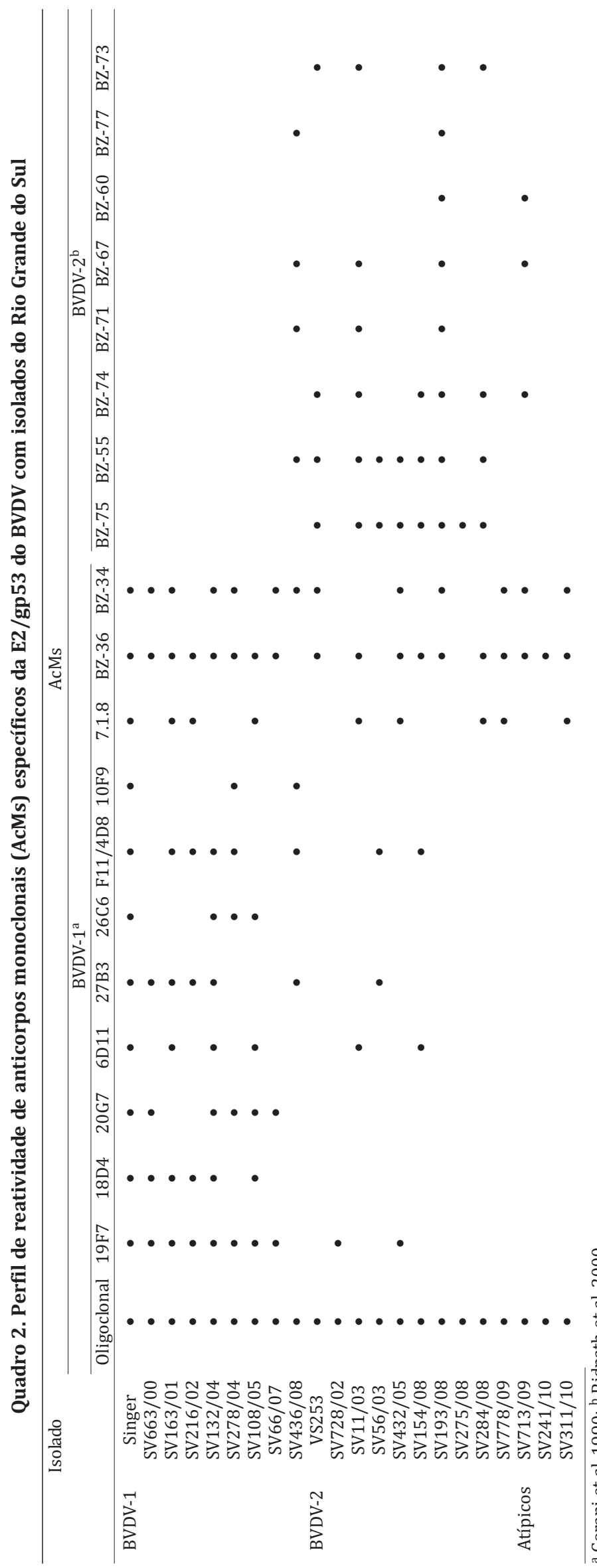

animal, pois se constituem em agentes recentes, cuja epidemiologia, biologia e patogenia ainda são desconhecidas (Schirrmeier et al. 2004, Stalder et al. 2005, 2007, Ridpath et al. 2010).

Além da variabilidade antigênica entre vírus de um mesmo genótipo, isolados de BVDV de genótipos diferentes são ainda mais diferentes entre si (Pellerin et al. 1994, Ridpath et al. 1994). Para analisar a variabilidade antigênica das amostras estudadas, inicialmente investigou-se a sua reatividade com um painel de AcMs específicos para a E2, a principal glicoproteína do envelope viral (Donis 1995). Parte desses AcMs foi produzida com uma cepa de BVDV-1 (Corapi et al. 1990) e parte com uma cepa de BVDV-2 (Ridpath et al. 2000). 0 perfil de reatividade dos AcMs com as amostras virais no teste de IFA está apresentado no Quadro 2 e ilustra a variabilidade antigênica do BVDV, especificamente da E2. Com exceção da cepa Singer (contra a qual grande parte dos AcMs do BVDV-1 foram produzidos), nenhum isolado de BVDV-1 foi reconhecido por todos os AcMs anti-BVDV-1. O isolado SV132/04 foi reconhecido por 9 AcMs, seguido pelos isolados SV163/01 e SV108/05 reconhecidos por 7 AcMs. Dentre os isolados de BVDV-2, o isolado SV193/08 foi reconhecido por todos os oito AcMs anti-BVDV-2, seguido do isolado SV11/ 03 (6 AcMs). Assim, mesmo isolados pertencentes ao mesmo genótipo apresentam importante variação na E2, o que resulta em reconhecimento variável por diferentes AcMs.

A reatividade de AcMs contra isolados de diferentes genótipos revela diferenças ainda mais marcantes. Grande parte dos isolados de BVDV-2 foi reconhecida por poucos AcMs produzidos contra o BVDV-1. Por outro lado, três AcMs do BVDV1 (7.1.8, BZ-36 e BZ-34 reconheceram vários isolados do BVDV-2, provavelmente reconhecendo epitopos compartilhados entre vírus dos dois genótipos. Dentre os isolados de BVDV1, apenas o SV436/08 foi reconhecido por AcMs do BVDV-2, confirmando as marcantes diferenças antigênicas entre os dois genótipos. Nesse sentido, esse isolado apresentou um padrão interessante de reatividade, sendo reconhecido por AcMs dos dois genótipos.

Dentre os isolados atípicos, o SV713/09 foi reconhecido por dois AcMs do BVDV-1 e três do BVDV-2. Ou seja, compartilha epitopos tanto com o BVDV-1 quanto com o BVDV-2. Já o isolado SV311/10 foi reconhecido por três AcMs do BVDV1, e o SV341/10 reagiu contra apenas um AcM do BVDV-1. Em resumo, os testes de reatividade com AcMs confirmaram a grande diversidade do BVDV, especialmente da glicoproteína E2. Além disso, os isolados atípicos mostraram-se diferentes antigenicamente tanto do BVDV1 quanto do BVDV-2.

A seguir, investigou-se a reatividade sorológica cruzada de anti-soro de cepas de referência (Singer[BVDV-1]); VS253[BVDV-2]) e de isolados brasileiros (IBSP-2 [BVDV-1]; VS26/2 [BVDV-2]) com as amostras isoladas (Fig.2). Embora seja difícil determinar com precisão os títulos necessários para conferir proteção, alguns autores consideram títulos de 80 como referência (Dubovi 1992, Fulton et al. 2003). Assim, os títulos dos anti-soros foram ajustados para 80/160 para os respectivos vírus homólogos e então testados contra os isolados. Pode-se observar que os anti-soros do BVDV-1 (Singer, IBSP-2) - apresentaram reatividade variável contra amostras do mesmo genótipo -, porém falharam em neutra- 
lizar praticamente a totalidade das amostras de BVDV-2 (Fig. 2). Da mesma forma, os anti-soros do BVDV-2 (VS253 e VS26/ 2) apresentaram atividade neutralizante variável contra as amostras do mesmo genótipo, porém apresentaram títulos muito baixos, ou mesmo indetectáveis, contra a maioria do isolados de BVDV-1. Assim, considerando-se a resposta sorológica induzida por eventuais vacinas, títulos neutralizantes de 80/160 contra um determinado genótipo não neutralizariam vírus de genótipo heterólogo. Esses resultados confirmam a grande diferença antigênica entre os dois genótipos e reforçam a necessidade de se incluir cepas de BVDV-1 e BVDV-2 nas vacinas.

A constatação da circulação de vírus dos dois genótipos no Brasil já resultou na inclusão de cepas de BVDV-2 (além de BVDV-1) em grande parte das vacinas comercializadas no país (Flores et al. 2005). Não obstante, a inclusão de amostras mais representativas da população viral circulante na população bovina - e que apresentem um espectro mais amplo de reatividade - poderia contribuir para uma maior eficácia das vacinas contra o BVDV. Nesse sentido, estudos mais abrangentes e detalhados sobre as características antigênicas dos vírus circulantes podem direcionar a formulação de vacinas mais protetoras. Em especial, a confirmação da circulação de pestivírus atípicos no país deve servir de alerta do ponto de vista de diagnóstico e também de estratégias de vacinação.

\section{REFERÊNCIAS}

Baker J.C. 1995. The clinical manifestations of bovine viral diarrhea virus infection. Vet. Clin. North Am. 11(3):425-445.

Becher P., Avalos-Ramirez R., Orlich M., Cedillo Rosales S., Konig M., Schweizer M., Stalder H., Schirrmeier H. \& Thiel H.J. 2003. Genetic and antigenic characterization of novel Pestivirus genotypes: implications for classification. Virology 311:96-104.

Botton S.A., Silva A.M., Brum M.C.S., Flores E.F. \& Weiblen R. 1998a. Antigenic characterization of Brazilian bovine viral diarrhea virus isolates by monoclonal antibodies and cross-neutralization. Braz. J. Med. Biol. Res. 31(11):1429-1438.

Botton S.A., Gil L.H.V.G., Silva A.M., Flores E.F., Weiblen R., Pituco M.E., Roehe P.M., Moojen V. \& Wendelstein A.C. 1998b. Caracterização preliminar de amostras do vírus da diarréia viral bovina (BVDV) isoladas no Brasil. Pesq. Vet. Bras. 18(2):84-92.

Canal C.W., Strasser M., Hertig C., Masuda A. \& Peterhans E. 1998. Detection of antibodies to bovine viral diarrhea virus (BVDV) and characterization of genomes of BVDV from Brazil. Vet. Microbiol. 63:85-97.

Collett M.S., Larson R., Gold C., Strick D., Dennis K., Anderson D.K. \& Purchio A.F. 1988. Molecular cloning and nucleotide sequence of the Pestivirus bovine viral diarrhea virus. Virology 165(1):191-199.

Corapi W.V., French T.W. \& Dubovi E.J. 1989. Severe thrombocytopenia in young calves experimentally infected with non cytopathic bovine viral diarrhea virus. J. Virol. 62:2823-2827.

Corapi W.V., Donis R.O. \& Dubovi E.J. 1990. Characterization of a panel of monoclonal antibodies and their use in the study of the antigenic diversity of bovine viral diarrhea virus. Am. J. Vet. Res. 51:1388-1394.

Cortez A., Heinemann M.B., Castro A.M.M.G., Soares R.M., Pinto A.M.V., Alfieri A.A., Flores E.F., Leite R.C. \& Richtzenhain L.J. 2006. Genetic characterization of Brazilian bovine viral diarrhea virus isolates by partial nucleotide sequencing of the 5'-UTR region. Pesq. Vet. Bras. 26(4):211216.

Donis R.O. 1995. Molecular biology of bovine viral diarrhea virus and its interactions with the host. Vet. Clin. North Am. 11(3):393-423.

Flores E.F., Weiblen R., Gil L.H.V.G., Tobias F.L., Lima M., Garcez D.C. \& Botton S.A. 2000. Diversidade antigênica de amostras do vírus da diarréia bovi- na isoladas no Brasil: implicações para o diagnóstico e estratégias de imunização. Arq. Bras. Med. Vet. Zootec. 52(1):11-17.

Flores E.F., Ridpath J.F., Weiblen R., Vogel F.S.F. \& Gil L.H.V.G. 2002. Phylogenetic analysis of Brazilian bovine viral diarrhea virus type 2 (BVDV-2) isolates: evidence for a subgenotype within BVDV-2. Virus Res. 87:51-60.

Flores E.F., Weiblen R., Vogel F.S.F., Roehe P.M., Alfieri A.A. \& Pituco E.M. 2005. A infecção pelo vírus da Diarréia Viral Bovina (BVDV) no Brasil: histórico, situação atual e perspectivas. Pesq. Vet. Bras. 25:125-134.

Fulton R.W., Ridpath J.F., Confer A.W., Saliki J.T., Burge L.T. \& Payton M.E. 2003. Bovine viral diarrhoea virus antigenic diversity: impact on disease and vaccination programmes. Biol. 31:89-95.

Gil L.H.V.G. 1998. Sequenciamento, análise filogenética e caracterização de polipeptídeos não-estruturais de amostras do Vírus da Diarréia Viral Bovina (BVDV). Dissertação de Mestrado em Medicina Veterinária, UFSM, Santa Maria, RS. 69p.

Hall T.A. BioEdit: A user-friendly biological sequence alignment editor and analysis program for Windows 95/98/NT. 1999. Nucleic Acids Symposium Series 41:95-98.

Horzinek M.C. 1991. Pestivirus: Taxonomic perspectives. Arch. Virol. (Suppl.3):1-5.

Liu L., Xia H., Baule C., Belák S. \& Wahlberg N. 2010. Effects of methodology and analysis strategy on robustness of Pestivirus phylogeny. Vet. Res. 147:47-52.

Minami F., Makoto N., Mika I., Tatsuhiko M., Hikaru T., Yoshiko J., Takeshi S., Michiko H., Yoshihisa S., Yoshihiro S., Katsuaki S. \& Hiroomi A. 2009. Reactivity and prevalence of neutralizing antibodies against Japanese strains of bovine viral diarrhea virus subgenotypes. Comp. Imm. Microbiol. Infect. Dis. (In publication)

Pellerin C., Hurk J., van den Lecomte J. \& Tussen P. 1994. Identification of a new group of bovine viral diarrhea virus strains associated with severe outbreaks and high mortalities. Virology 203(2):260-268.

Ridpath J.F., Bolin S.R. \& Dubovi E.J. 1994. Segregation of bovine viral diarrhea virus into genotypes. Virol. 206(1):66-74.

Ridpath J.F. \& Bolin S.R. 1998. Differentiation of types 1a, $1 \mathrm{~b}$ and 2 bovine viral diarrhea virus (BVDV) by PCR. Mol. Cell Probes 12(2):101-106.

Ridpath J.F., Neill J.D., Frey M. \& Landgraf J.G. 2000. Phylogenetic, antigenic and clinical characterization of type 2 BVDV from North America. Vet. Microbiol. 77:145-155.

Ridpath J.F. 2003. BVDV genotypes and biotypes: practical implications for diagnosis and control. Biol. 31:127-131.

Ridpath J.F. 2005. Practical significance of heterogeneity among BVDV strains: Impact of biotype and genotype on U.S. control programs. Prev. Vet. Med. 72(1/2):17-30.

Ridpath J.F. 2010. Bovine viral diarrhea virus: Global status. Vet. Clin. Food Anim. 26:105-121.

Ridpath J.F., Fulton R.W., Kirkland P.D. \& Neill J.D. 2010. Prevalence and antigenic differences observed between bovine viral diarrhea virus subgenotypes isolated from cattle in Australia and feedlots in the southwestern United States. J. Vet. Diagn. Invest. 22:184-191.

Schirrmeier H., Strebelow G., Depner K., Hoffman B. \& Beer M. 2004. Genetic and antigenic characterization of an atypical Pestivirus isolate, a putative member of a novel Pestivirus species. J. Gen. Virol. 85:3647-3652.

Staden R. 1996. The Staden sequence analysis package. Molecular Biotechnology 5:223-241.

Stahl K., Kampa J., Alenius S., Persson A.W., Baule C., Aiumlamai S. \& Belák S. 2007. Natural infection of cattle with an atypical "Hobi"-like pestivirusImplications for BVD control and for the safety of biological products. Vet. Res. 38:517-523.

Stalder H.P., Meier P., Pfaffen G., Wageck-Canal C., Rufenacht J., Schaller P., Bachofen C., Marti S., Vogt H.R. \& Peterhans E. 2005. Genetic heterogeneity of pestivirus of ruminats in Switzerland. Prev. Vet. Med. 72(1/2):37-41.

Vilcek S., Paton D.J., Durkovic B., Strojny L., Ibata G., Moussa A., Loitsch A., Rossmanith W., Veja S., Scicluna M.T. \& Palfi V. 2001. Bovine viral diarrhea virus genotype 1 can be separated into at least eleven genetic groups. Arq. Virol. 146(1):99-115. 